A chave estrela. Primo Levi (São Paulo: Companhia das Letras, 2008.) Tradução de Maurício Santana Dias.

\title{
O tRABALHO: A CHAVE PARA A LIBERDADE
}

Primo Levi é autor de vários livros e já tem seu lugar no sistema literário brasileiro. Praticamente todas as suas obras foram traduzidas no Brasil nos últimos vinte anos. Seu livro mais famoso e esgotadíssimo, É isto um homem?, de 1947, publicado no Brasil em 1988 pela editora Rocco, é o testemunho da experiência, recuperada pelos fios da memória, vivenciada durante o tempo (1944) em que passou preso num dos maiores campos de concentração nazista: Auschwitz. A trégua, lançado no mercado editorial italiano em 1963, e publicado no Brasil em 1997, pela Companhia das Letras, aborda a viagem picaresca de retorno do lager. Uma espécie de continuação do testemunho iniciado em $E$ isto um homem?. Com o fim da guerra, chega a hora do retorno e o que se vê é uma Europa destruída e em ruínas. Uma viagem, enfim, em busca da liberdade após a experiência do limite extremo do horror e da miséria em Auschwitz. Esse limite da sobrevivência representado e testemunhado por Levi, de uma quase total degradação humana, tem aberto caminhos para recentes estudos e reflexões no campo da ética, como evidencia o filósofo italiano Giorgio Agamben.

O que resta de Auschwitz (2008) é o título-pergunta de um dos livros de Agamben, no qual o filósofo questiona "como narrar o inarrável". Aqui o testemunho é visto como um documento histórico, como um dos inúmeros indícios necessários à construção da narrativa histórica - sem claro esquecer das delimitaçôes de um relato individual. Logo nas primeiras linhas do prefácio de $E$ isto um homem? Levi afirma: "Este meu livro, portanto, nada acrescenta, quanto a detalhes atrozes, ao que já é bem conhecido dos leitores de todo o mundo com referência ao tema doloroso dos campos de extermínio. Ele não foi escrito para fazer novas denúncias; poderá antes fornecer documentos para um sereno estudo de certos aspectos da vida humana... A história dos campos de extermínio deveria ser compreendida por todos como sinistro sinal de perigo." Para a proposta de análise de Agamben o relato testemunhal de Primo Levi passa a ser fundamental, como um daqueles que ex- 
perienciaram e sobreviveram a Auschwitz - o lugar do humano e do inumano, da morte e da vida.

A chave estrela, que ganhou os renomados prêmios italianos Strega e Viareggio, acaba de chegar ao mercado editorial brasileiro pela Companhia das Letras e foi publicado na Itália em 1978. Aqui, não há mais a representação focada e direta dos campos de concentração. Este livro é uma espécie de homenagem ao trabalho, ao trabalho criativo, e aos técnicos que nos anos 60 e 70, anos do boom da economia, viajaram pelo mundo representando o crescimento e a indústria italiana. Alguns binômios podem ser identificados logo no início da leitura: a construção (engenho/engenharia/ capacidade de construir) ocupa o lugar da destruição e das ruínas, $\mathrm{o}$ aprisionamento cede lugar à liberdade e à possibilidade de ir e vir. Os relatos do vivido não são mais fruto de um trauma letal, e sim de uma vida que se renova a cada viagem, a cada projeto realizado e construído e a cada novo espaço conhecido.

Apesar de alguns detalhes remeterem ao tempo vivido em Auschwitz, o pano de fundo não é mais a horrível e perversa realidade do campo de concentração. Faussone é um trabalhador-viajante que sai pelo mundo, do Ocidente ao Oriente, erguendo construçôes e instalações: andaime em forma de torre, pontes, prédios, túneis. Um puzzle de relatos entrecortados, no qual o narrador, um atento ouvinte, tenta seguir os fios da trama que lhe é tecida por Faussone: “... é ele (Faussone) que tem alguma aventura ou desventura a contar e a debulha toda num jato, com aqueles seus modos desleixados aos quais até já me habituei, sem se deixar interromper senão por algum breve pedido de esclarecimento. $\mathrm{O}$ resultado é que há uma tendência maior ao monólogo do que ao diálogo...” (p. 53). Contudo, como dirá o narrador, no capítulo "Off-shore", é possível sim seguir uma história com interesse, porém nem sempre com "total compreensão", porque para entender certas aventuras é preciso vivê-las ou pelo menos vê-las” (p. 73). É necessário, portanto, ser uma testemunha, seja a partir do ponto de vista daquele que a vivenciou ou daquele que a observou.

Assim, o que se tem é um longo monólogo mascarado por diálogos entre um operário - Faussone - e um intelectual, um químico de vernizes que quer ser escritor. Eles se conhecem numa das viagens/construções empreendidas por Faussone e é ele que dá o tom das muitas histórias que irão ser contadas "Ah, não: tudo eu não posso contar. Ou bem lhe digo o lugar, ou então lhe conto o 
fato - mas eu, se fosse o senhor, escolheria o fato, porque é um fato e tanto. Depois, se o senhor quiser mesmo recontá-lo, basta trabalhar em cima dele, [...], pronto, aí está uma bela história; e, apesar de eu ser mais jovem que o senhor, história é o que não me falta" (p. 7). A partir desse momento, a narrativa começa a ser narrada em primeira pessoa, na voz do químico, intercalada com as histórias do montador Faussone.

Na verdade, seu nome é Libertino Faussone. A família quis chamá-lo de Libero, mas foi impedida pelas "normas" do regime fascista. Libertino é, de qualquer forma, um elogio à liberdade. Faussone, o sobrenome, deriva de faus, palavra que em dialeto piemontês significa falso. Se a liberdade está presente no nome para este personagem, a questão do falso também está presente e se concretiza na última página do livro de Levi, com a citação da nota ao Typhoon de Conrad. Neste sentido, o trabalho - tema central -, presente desde a primeira página, "[...] o refeitório para estrangeiros de uma fábrica [...]", pode ser visto como a chave para a liberdade. Assim, a expressão Arbeit macht frei - "o trabalho liberta" - na entrada do portão de Auschwitz é subvertido, a partir dos relatos de Faussone, no refeitório, no canteiro de obras, no barco... A paródia desumana do trabalho no campo de concentração, o trabalho-castigo-morte, que conduz a um fim terrível e sem retorno, é desfeito e o que se tem é a visão do trabalho que traz de volta e reafirma a vida.

Dessa forma, o que é feito e produzido pelo homem passa a ter um valor e a significar também a liberdade: o trabalho leva à liberdade (está no nome de Faussone e se concretiza nas inúmeras viagens realizadas). Faussone, uma Sherazade operária que narra as experiências de viagens e trabalhos, pode ser compreendido como o homo faber, para quem o trabalho é necessário e, ao mesmo tempo, liberta. Para se ter uma ideia da importância do trabalho, no seu relato ele o compara ao primeiro amor, dando a esta atividade uma "aura" que pode levar à felicidade: "O problema é que dou a alma em todos os trabalhos, o senhor sabe, até nos mais estúpidos: aliás, quanto mais estúpidos, mais eu me entrego. Para mim, cada trabalho que começo é como um primeiro amor" (p. 48).

Uma espécie de Sherazade é apresentada nas vestes desse viajante-operário, que relata diferentes serviços realizados e pessoas encontradas - como o companheiro macaco ou o chefe inexperiente-, e faz uso de certas expressōes e perguntas para costurar e dar continuidade à sua trama: "Bem, o que você ainda quer saber?" (p. 42). 
Essa é uma das estratégias de Faussone para alinhavar as diferentes histórias e manter o seu ouvinte (o real narrador do livro). Esse tipo de narrador da tradição oral, recuperado por Walter Benjamin no famoso ensaio sobre Nicolai Leskov, está também nas entrelinhas da fala do químico de vernizes - o ouvinte: “De fato, como há uma arte de narrar, solidamente codificada ao longo de mil provas e erros, do mesmo modo há uma arte da escuta, igualmente antiga e nobre, para a qual, no entanto, ao que eu saiba, nunca foi formulada uma norma. Entretanto cada narrador sabe por experiência que a cada narração o ouvinte acrescenta uma contribuição decisiva [...]” (p. 40). Essa construção narrativa pode remeter o leitor atento a um outro livro da literatura italiana: As cidades invisiveis, de Italo Calvino. Publicado em 1972, poucos anos antes de $A$ chave estrela, a obra de Calvino apresenta um esquema sherazadiano parecido: um viajante-explorador, Marco Polo, e um ouvinte, o imperador Kublai Khan, que mesmo desconfiando continua a seguir "encantado" os fios dos relatos tecidos pelo navegador veneziano.

Em $A$ chave estrela, a presença do holocausto se liquefaz quase completamente e pode ser identificada em algumas referências, como no capítulo intitulado "Clausura", em que Faussone diz "[...] seja como for, veja bem, nunca peguei nenhum trabalho na Alemanha, nunca simpatizei com aquelas terras, me arranjo em várias línguas, falo até um pouco de árabe e de japonês, mas não sei uma palavra de alemão. Dia desses quero lhe contar a história de meu pai prisioneiro de guerra, mas não é como a sua, está mais para o cômico" (p.15). Uma referência à experiência trágica da guerra e à brutal realidade dos lager e, ao mesmo tempo, um afastamento por nunca ter recebido ou aceito um trabalho na Alemanha nem mesmo saber alemão, apesar de conhecer uma série de línguas que "falava incorretamente, mas com fluência”. No livro há também muitos indícios autobiográficos, como este acima e a profissão do intelectual-narrador, interlocutor de Faussone, que é químico de vernizes e pretende ser escritor. É interessante também pensar na relação que se apresenta entre Faussone, que constrói edificaçôes, e esse narrador, um profissional da química, que pretende construir narrativas literárias.

Esse e os outros livros de Pimo Levi, talvez de forma mais nítida, mostram como a literatura e, em particular, o ato da escrita são frutos de um complexo envolvimento com o mundo no qual se está inserido. Ler Primo Levi sem ter pelo menos uma noção de sua experiência como um cidadão italiano deportado é talvez ler sua obra pela metade. O seu testemunho enquanto escritor está ligado sim às 
suas vivências individuais, mas também a um determinado momento da história humana que permeia e emana da sua produção.

A leitura de $A$ chave estrela pode lembrar ao leitor do encontro entre Primo Levi e Philip Roth, retratado pelo escritor americano no livro de entrevistas Entre nós, publicado no final de 2008 pela Companhia das Letras. É numa sexta-feira do mês de setembro de 1986 que Levi leva Roth para conhecer um pouco dos seus espaços: a casa, o escritório e a fábrica de tintas, onde ele trabalhou como químico pesquisador e depois diretor. E nesse encontro-entrevista o próprio Levi fala sobre o trabalho, tema já enfocado em outros livros como $A$ tabela periódica (Itália, 1975 - Brasil, 2001): "Estou convencido de que os seres humanos normais são biologicamente constituídos para desempenhar uma atividade voltada para um objetivo, e que o ócio, ou o trabalho sem objetivo (como Arbeit de Auschwitz), gera sofrimento e atrofia. No meu caso, como no caso do meu alter ego, Faussone, o trabalho se identifica com a resolução de problemas." Poucos meses depois desse encontro, em 11 de abril de 1987, Levi cai das escadas de sua casa em Turim e morre. As discussões sobre a hipótese de suicídio são ainda defendidas e contestadas.

Andreia Guerini \& Patricia Peterle (UFSC) 